Illinois State University

ISU ReD: Research and eData

Theses and Dissertations

$10-28-2020$

\title{
Social Media Rumination: The Impact Of Materialistic Value Orientation
}

Keeley Hynes

Illinois State University, khynes@ilstu.edu

Follow this and additional works at: https://ir.library.illinoisstate.edu/etd

Part of the Developmental Psychology Commons, Mass Communication Commons, and the Quantitative, Qualitative, Comparative, and Historical Methodologies Commons

\section{Recommended Citation}

Hynes, Keeley, "Social Media Rumination: The Impact Of Materialistic Value Orientation" (2020). Theses and Dissertations. 1334.

https://ir.library.illinoisstate.edu/etd/1334

This Thesis is brought to you for free and open access by ISU ReD: Research and eData. It has been accepted for inclusion in Theses and Dissertations by an authorized administrator of ISU ReD: Research and eData. For more information, please contact ISUReD@ilstu.edu. 


\section{SOCIAL MEDIA RUMINATION: THE IMPACT OF MATERIALISTIC VALUE \\ ORIENTATION}

\section{KEELEY HYNES}

32 Pages

Previous research demonstrates that ruminating on social media content is associated with greater mental distress (Yang, Holden, Carter, \& Webb, 2018). However, it is unclear what factors are associated with rumination. Using Self-Determination Theory (SDT) as a theoretical framework, this study examined how materialistic value orientation (MVO) predicted social media rumination in a sample of racially and socioeconomically diverse high school students at two waves of time. Those who are more materialistic value the means by which to gain possessions, and extrinsic life-goals associated with MVO are aimed at garnering external reinforcers such as money and social status (Richins \& Dawson, 1992; Deci \& Ryan, 2000). MVO and social media rumination were measured at Wave 1 and again four months later at Wave 2, as testing these variables' relationships over time allows for bidirectional data that can inform how MVO impacts social media rumination and the opposite. A cross-lag analysis of social media rumination and MVO among 119 adolescents enrolled in a relationship education program indicated those with higher MVO at Wave 1 were more likely to ruminate over their social media more at Wave 2 than those with lower MVO at Wave 1. These findings suggest interventions targeting life-goal orientation and rumination among adolescents are warranted.

KEYWORDS: Social media, life goal orientation, materialistic value orientation, rumination 
SOCIAL MEDIA RUMINATION: THE IMPACT OF MATERIALISTIC VALUE ORIENTATION

\title{
KEELEY HYNES
}

\author{
A Thesis Submitted in Partial \\ Fulfillment of the Requirements \\ for the Degree of \\ MASTER OF SCIENCE \\ Department of Psychology \\ ILLINOIS STATE UNIVERSITY
}


Copyright 2020 Keeley Hynes 
SOCIAL MEDIA RUMINATION: THE IMPACT OF MATERIALISTIC VALUE ORIENTATION

\section{KEELEY HYNES}

COMMITTEE MEMBERS:

Daniel G. Lannin, Chair

Margaret Nauta 


\section{ACKNOWLEDGMENTS}

I would like to thank my committee members, Drs. Daniel Lannin and Margaret Nauta, for their support with this project. I would also like to thank my reader, Dr. Julie Campbell, for her important feedback. Further, special thanks are warranted to the CARE4U undergraduate and graduate research assistants, program facilitators, Drs. Jeremy Kanter, Luke Russell, Leandra Parris, and Ani Yazedjian. I would like to thank the Illinois State University Department of Psychology and Graduate School for supporting student research. Additionally, my cohort, family, and friends have demonstrated consistent understanding and encouragement throughout this process, and this project would not be complete without them.

K.H. 


\section{CONTENTS}

Page

ACKNOWLEDGMENTS

CONTENTS

TABLES $\quad$ iv

FIGURES

CHAPTER I: INTRODUCTION 1

Self-Determination Theory and Materialistic Value Orientation 2

$\begin{array}{ll}\text { Rumination } & 4\end{array}$

$\begin{array}{ll}\text { Social Media Rumination } & 5\end{array}$

$\begin{array}{ll}\text { Overview of the Present Study } & 8\end{array}$

$\begin{array}{ll}\text { CHAPTER II: METHOD } & 10\end{array}$

$\begin{array}{ll}\text { Design } & 10\end{array}$

$\begin{array}{ll}\text { Participants } & 10\end{array}$

$\begin{array}{ll}\text { Measures } & 11\end{array}$

$\begin{array}{ll}\text { Procedure } & 13\end{array}$

CHAPTER III: RESULTS 14

$\begin{array}{ll}\text { Preliminary Analyses } & 14\end{array}$

$\begin{array}{ll}\text { Primary Analyses } & 14\end{array}$

$\begin{array}{ll}\text { CHAPTER IV: DISCUSSION } & 18\end{array}$

$\begin{array}{ll}\text { Implications } & 19\end{array}$

$\begin{array}{ll}\text { Limitations and Future Directions } & 21\end{array}$

$\begin{array}{ll}\text { Conclusion } & 22\end{array}$ 
REFERENCES

APPENDIX A: SOCIAL MEDIA RUMINATION, MATERIALISTIC VALUE

ORIENTATION, AND DEMOGRAPHICS

APPENDIX B: MATERIALISTIC VALUE ORIENTATION AND SOCIAL MEDIA

RUMINATION 


\section{TABLES}

Table

Page

1. Social Media Rumination, Materialistic Value Orientation, and Demographics

2. Materialistic Value Orientation and Social Media Rumination 


\section{FIGURES}

Figure

Page

1. All Models Tested 


\section{CHAPTER I: INTRODUCTION}

As usage of videogames, streaming services, and social media becomes pervasive among youth (Anderson \& Jiang, 2018), there is a need for research to explore its effects on mental health (Espinoza \& Juvonen, 2011). Increased use can lead to numerous mental health issues. For example, increased Internet use has been linked to Internet addiction, which is linked to maladaptive coping strategies and high levels of depression and anxiety (McNicol, \& Thorsteinsson, 2017). Additionally, social media sites — some of youth's primary online destinations - can be mediums where victimization can occur; those who are victimized online are also at risk for increased depressive symptoms and rumination (Feinstein, Bhatia, \& Davila, 2014; Espinoza \& Juvonen, 2011). Given social media's central role in the lives of many youth, it is conceivable that youth may ruminate over their social media postings (Feinstein et al., 2014); such rumination could evoke negative consequences for mental health. Rumination may be a key psychological process that maintains negative moods and exacerbates mental health problems, leading to increasing psychological distress (Nolen-Hoeksema, 1991; Wei, Shaffer, Young, \& Zakalik, 2005); however, it may be beneficial to examine predictors of rumination that are specific to social media (i.e., social media rumination).

Orientation toward certain life-goals may be predictive of social media rumination because how youth address deeper organismic needs and underlying motivation may influence their efforts to connect with others online (Ryan \& Deci, 2000). Specifically, materialistic value orientation (MVO) - prioritizing values and goals related to consumerism, consumption, and social status - may be linked to greater social media rumination, because MVO reflects efforts to gain external approval (Kasser, 2016). Therefore, the present study proposes to examine the 
relationships between MVO and social media rumination over two waves of data in a sample of diverse adolescents.

\section{Self-Determination Theory and Materialistic Value Orientation}

According to Self-Determination Theory (SDT), humans function best when fulfilling basic psychological needs that include competence, relatedness, and autonomy (Deci \& Ryan, 2000). Individuals engage in goal-directed behavior, driven by motivation to satisfy their needs, and these can be indicative of adaptive/maladaptive development and behavior (Deci \& Ryan, 2012). Intrinsic life-goals are overarching goals that aim to meet needs related to basic psychological needs of competence, relatedness, and autonomy. Individuals may seek out activities in service of their overarching intrinsic life-goals, thus meeting the underlying needs that correspond to those life-goals. For example, communicating with a friend about a common interest can satisfy relatedness needs, seeking out a new hobby such as learning a musical instrument could satisfy needs for competence, and deciding on one's own college major could satisfy needs for autonomy. When these basic needs are regularly met, individuals tend to experience productive functioning and well-being (Deci \& Ryan, 2000).

Conversely, when identifying and satisfying intrinsic needs seems less feasible, individuals seek extrinsic rewards that provide temporary psychological relief (Deci \& Ryan, 2000). Life-goals that are motivated by external reward rather than internal need-satisfaction, are referred to as $\mathrm{MVO}$ — and include striving towards social status, having nice possessions, financial success, and "having the right image" (Kasser \& Kanner, 2004). Those who are more materialistic value the means by which to gain possessions, and extrinsic life-goals associated with MVO are aimed at garnering external reinforcers such as fame, money, and social status (Richins \& Dawson, 1992; Deci \& Ryan, 2000). Being oriented toward extrinsic life-goals may 
indicate that an individual substitutes meeting intrinsic needs with thoughts and activities that are short-term rewards but fails to experience long-term contentment and well-being (Deci \& Ryan, 2012). For example, if an individual is not directly satisfying their need for relatedness, they may seek external validation by cultivating "the right image", purchasing new clothing, and getting an expensive haircut. While these efforts might elicit some social approval (e.g., "your hair looks nice"), they may not directly support the creation and maintenance of close relationships that may be needed to satisfy basic psychological needs for relatedness, potentially leading to greater distress. Support of this notion includes the finding that threats to the fulfillment of basic psychological needs are linked to higher levels of anxiety and depression among adults, as meeting psychological needs can significantly mediate the relationship between attachment and distress (Wei et al., 2005). Indeed, while intrinsic goal-orientation has been positively associated with subjective well-being and lower immorality, extrinsic goal-orientation has been negatively associated with these variables (Sheldon, Sommet, Corcoran, \& Elliot, 2018). The extent to which external validation relates to rumination is less documented, but there is evidence to suggest that MVO is linked to insecurity (Kasser \& Sheldon, 2000), and those who are more insecure have been shown to ruminate more than those who are not (Burnette, Davis, Green, Worthington, Bradfield, 2009).

The harmful impact of over-prioritizing extrinsic life-goals at the expense of intrinsic life-goals (i.e., MVO) is well-analyzed (Kasser, 2016). MVO is linked to decreased gratitude and life satisfaction (Tsang, Carpenter, Roberts, Frisch, \& Carlisle, 2014), as well as greater interpersonal problems and increased media use; conversely, intrinsic need satisfaction of competence and relatedness predict greater well-being in young adults and positive interpersonal and intrapersonal outcomes (Kasser, 2016; León, \& Núñez, 2013). Intrapersonal problems can be 
impacted by MVO as well, showing increased anxiety symptoms, unhappiness, and lowered selfactualization (Kasser \& Ahuvia, 2002). Though MVO may influence social media usage, social media usage may also influence MVO, as college students with more exposure to Facebook demonstrate lower self-esteem and increased MVO in adolescents (Chaplin \& John, 2007; Kamal, Chu, \& Pedram, 2013; Vogel, Rose, Roberts, \& Eckles, 2014). Those with MVO may substitute genuine psychological need satisfaction by attempting to garner praise and external validation on social media platforms through posts, shares, comments, and likes. The rewards of such online efforts are contingent on others' behaviors, and those who are looking for online validation may feel unsettled.

\section{Rumination}

Maladaptive rumination is identified as continually mulling over one's problems without acting to solve those problems (Nolen-Hoeksema, 1991). Maladaptive rumination is considered as constantly thinking about one's problems and not acting to solve them, whereas adaptive rumination involves acting to solve one's problems after thinking through solutions. Maladaptive rumination, or "toxic brooding," predicts greater depressive symptoms, psychological distress, and development of psychopathology (Grierson, Hickie, Naismith, \& Scott, 2016). Rumination has also been shown to be a predictor of future psychological distress, as reported from a longitudinal study of Swedish adolescents (Mazzer, Boersma, \& Linton, 2019). Additionally, evidence shows longitudinal effects of rumination, in which rumination can interfere with coping with depression and anxiety symptoms (Grierson et al., 2016). Wang et al. (2018) also found that rumination fully mediated the relationship between online self-presentation and depression in high school students. Although recent studies have shown that rumination can mediate adaptive behaviors like ignoring distracting information and persisting with thought on a specific 
problem, researchers propose that chronic rumination increases the risk of presenting depressive symptoms (DeJong, Fox, \& Stein, 2019). In addition, a study by Mitra and Rangaswamy (2019) showed that rumination among 18 to 25 -year-olds from India mediated social media addiction and depression. There is also evidence that this toxic brooding mediates transdiagnosis of depression and anxiety in adolescents (McLaughlin \& Nolen-Hoeksema, 2011). These results demonstrate the importance of discovering other ways rumination occurs in hopes of informing psychological treatment and prevention of mental health disorders.

\section{Social Media Rumination}

Despite the decades of research exploring rumination and its effects, the idea of social media rumination has not been investigated. The Internet is available and regularly used for social media by adolescents and young adults with access to a smartphone, even when experiencing homelessness, demonstrating high accessibility (VonHoltz et al., 2018). Further, experiencing more empathy towards another individual's distress could increase their depressive symptoms (Schwartz-Mette \& Smith, 2018). This idea is important, as adolescents are constantly on platforms that reinforce interpersonal relationships and exposure to others' lives. Features that enhance interpersonal interactions like the ability to comment, like, and share others' posts promote a platform for conversations about personal issues, mental health, and other problems. This set up, and the constant access to attention from others, could very well lead to online corumination.

In this study, social media rumination is defined as a participant's self-reported level of thinking about their activity and others' experiences on social media (e.g., the extent to which they think before posting, worrying about their attractiveness on social media), including theirs and others' posts and the consequences of posts. People who more align with MVO may be more 
likely to ruminate over social media, as they could be worried about self-presentation, and extrinsic rewards (e.g., being called pretty) can be more contingent on others (Chua \& Chang, 2016). This contingency on others may require more vigilant surveillance of one's social media accounts, which could call for social comparison of richness, popularity, and social status, qualities relative to others' standings. Those who use Facebook more have been shown to engage in more social comparison, which may evoke threats to self-esteem and other psychological factors (Vogel, Rose, Okdie, Eckles, \& Franz, 2015). Psychological distress can impact multiple areas of an individual's life, reflecting a need to learn more about how to avoid seeking external validation or treat this negative consequence.

One aspect of social media related to materialistic values that may influence rumination of adolescents is advertising. Advertisements appear throughout social media platforms, and adolescents' viewing of advertisements in the media (i.e., television, magazines, and newspapers) has been shown to have a direct impact on their materialistic values, which increases communication to peers about advertisements (Chia, 2010). This communication may occur on social media platforms, and there may be pressure from MVO-related thoughts to frequently express "correct" knowledge about the latest trends seen on advertisements. Advertisements may also contribute to distress for people with MVO, as expectations presented in advertisements can be unrealistic (e.g., we should all have the expensive items displayed). Further, the link between anxious attachment and MVO, mediated by loneliness, may suggest that those who have more materialistic values worry about social interactions more than those who have less materialistic values (Norris, Lambert, DeWall, Fincham, 2012). Furthermore, Luyckx, Duriez, Green, and Negru-Subtirica (2016) found that a more intrinsic life-goal 
orientation in college students negatively predicted rumination. Therefore, social media activities may function as a need-substitute for those with MVO, and this may lead to greater rumination.

Social media rumination — the tendency to repetitively think about one's social media posts, related situational factors, and consequences of those posts (cf. Lannin, Parris, Yazedjian, \& Hynes, in progress; Nolen-Hoeksema, 1991) — may demonstrate a cyclical recursive process with mental distress (Mazzer et al., 2019). Social media is an important area of study given nearly half of teens indicate that they are "online almost constantly" and nearly a quarter of teens report social media has a negative effect for reasons such as bullying and lack of in-person contact (Anderson \& Jiang, 2018). Features like commenting, sharing, and liking others' posts on social media platforms allow for multiple forms of communication, but some people may feel left out when seeing others interact to a high degree. Fear of missing out (FoMo) can be a symptom of seeing friends interacting with others and is associated with extrinsic and amotivation (Alt, 2015). Further, college students using social media often compare themselves to others, which can lead to ruminating more over others and their posts, in turn creating more identity distress (Yang et al., 2018). Additionally, more Facebook use by college students has been linked to greater levels of brooding and social anxiety disorder symptoms, as well as more exposure to Facebook has been shown to be linked to lower self-esteem (Shaw, Timpano, Tran, \& Joormann, 2015; Vogel et al., 2014). These results indicate there may be negative impacts of chronic use of social media but do not explain why these effects occur. Therefore, understanding predictors of social media rumination may be an important area of study.

A gap in research demonstrates the need to explore the connection between MVO and social media rumination. During adolescence, youth think about what they would like to accomplish in their lives, and these life-goals reflect strivings related to intrinsic or extrinsic 
motivation. According to SDT, all human beings thrive when satisfying basic psychological needs such as relatedness, competence, and autonomy (Deci \& Ryan, 2000). It is likely that social media platforms are mediums for pursuing intrinsic aims, but also MVO aims - due to the social comparisons that platforms can evoke. Further, research has shown adolescents born between 1946 and 1961 and adolescents born between 1982 and 1995 have lower intrinsic goal orientation than those born between 1962 and 1981 measured at the same age (Twenge, Campbell, \& Freeman, 2012). Less research has shown if this pattern has continued for Generation Z adolescents (i.e., born between 1996 and 2010) and how their life-goal orientation compares to other generations. The connection, if any, between MVO and social media rumination may provide insight into how youth are living and adapting to the social media age of today.

\section{Overview of the Present Study}

In the present study, I will use two waves of data to explore the relationship between MVO, as outlined in SDT, and social media rumination among at-risk youth. As previous studies focusing on social media have included mostly college students (Yang et al., 2018; Vogel et al., 2014), little is known about what affects adolescents' social media activity. The study tested this relationship using secondary data analysis through a cross-lagged panel design with a sample of adolescents from predominantly low-income homes. I hypothesized that high school students who have higher MVO (i.e., a positive score when intrinsic life-goal orientation is subtracted from than extrinsic life-goal orientation) would be more likely to ruminate on their social media content over time because extrinsic need satisfaction is contingent on others' transient responses (i.e., validations) and may require more energy and attention to maintain a social media presence that provides those rewards. Though there is evidence that rumination may increase MVO over 
time (Chaplin \& John, 2007; Kamal, Chu, \& Pedram, 2013; Vogel et al., 2014), given the strength of evidence suggesting opposite (Burnette et al., 2009; Wang et al., 2018; Chua \& Chang, 2016; Vogel et al., 2015), I predict the relationship showing MVO impacts social media rumination will be stronger than the relationship showing social media rumination impacts MVO. Social media rumination will be assessed via items of a new scale; therefore, I will examine the validity of those items by exploring the relationship of social media use and distress (Vogel et al., 2015), linking social media rumination and distress. 


\section{CHAPTER II: METHOD}

\section{Design}

This present 2-wave study assessed the directional relationships between MVO and social media rumination using a cross-lagged panel design through secondary data analysis. Data was derived from surveys taken four months apart. Champaign Area Relationship Education for Youth $(C A R E 4 U)$ is a program funded by the U.S. Department of Health and Human Services, Administration for Children and Families (Grant \#90FM0076). This program teaches at-risk youth how to maintain healthy relationships through learning adaptive communication skills and warning signs of unhealthy relationships from the Love Notes curriculum (Pearson, 2016). Some lessons involve information about online presence, but there are no lessons explicitly stating how to spend time on social media. Participants are recruited from local high schools and alternative schools.

\section{Participants}

In all, 231 adolescents completed the Love Notes curriculum (Pearson, 2016) with CARE4U. Of those participants, 178 adolescents completed the pretest, and 158 adolescents completed the posttest. Data from this study derived from adolescents $(N=119)$ who completed both pretest and posttest Qualtrics surveys on iPads to provide quantitative data on social media rumination and life goal orientation. Most participants identified themselves as female (75.6\%), with almost one quarter being male $(23.5 \%)$, and a very small percent being transgender $(0.8 \%)$. The average age of participants was 15.84 years $(S D=0.83 ; 14-18)$ enrolled as a Freshman (2.5\%), Sophomore (38.7\%), Junior (41.2\%), and Senior (17.6\%). The diverse sample of participants included those who identify as Black/African American (52.1\%), White/European American (17.6\%), Asian/Asian American (13.4\%), Hispanic/Latinx (6.7\%), Native American 
(4.2\%), and Other (5.9\%). Most participants reported receiving assistance such as Temporary Assistance of Needy Families, Supplemental Security Income, Social Security Disability Insurance, Women, Infants, and Children, Housing Choice Voucher, Supplemental Nutrition Assistance Program, Free or Reduced Lunch, or Cash Assistance (68.1\%).

The Aspiration Index. The Aspiration Index (Kasser \& Ryan, 1993) assessed participants' life goal orientation. Of the original 105 items, 35 items assessed the degree to which a participant's life-goals are more intrinsically $(\alpha=.89)$ or extrinsically oriented. $(\alpha=$ .93). These items were rated on a 7-point Likert scale of what individuals hope to accomplish (e.g., $1=$ not at all, 7 = very). Items relate to seven categories of aspirations: wealth (e.g., "Be a very wealthy person") fame (e.g., "Be admired by lots of different people"), image (e.g., “Achieve the 'look' I've been after”), personal growth (e.g., "Grow and learn new things”), relationships (e.g., "Have committed, intimate relationships"), community (e.g., "Help people in need") and health (e.g., "Be physically healthy"). Wealth, fame, and image represent extrinsic goals, while personal growth, relationships, community, and health represent intrinsic goals. In this study, the difference between an individual's intrinsic and extrinsic orientation reveals the individual's level of MVO (i.e., those who score higher on extrinsic goals than intrinsic goals will show their level of MVO), as MVO is more closely related to extrinsic life-goal orientation than intrinsic life-goal orientation (Kasser, 2016).

Social Media Rumination Scale. The Social Media Rumination Scale (SMRS) was developed specifically for this study and asked participants to indicate the degree to which they thought or worried about social media activities. To determine the structure of the SMRS, a series of analyses were conducted. First, a parallel analysis was conducted to determine factor retention (Hayton, Allen, \& Scarpello, 2004) followed by a principle component analysis. Of the 
19 original items (e.g., "I worry about how people will react to my social media posts."), 7 were dropped following a principle components analysis. Through a series of parallel analyses, items were dropped if they had a loading of less than .50 or loaded on both factors. This process resulted in a one-factor model which was supported by a parallel analysis, scree plot, and the Kaiser criterion of an eigenvalue greater than one. This led to the final measure resulting in a reliable 12-item scale $(\alpha=.88, \omega=.87,95 \% \mathrm{CI}=[0.84,0.90])$. Participants reported their social media rumination on a scale of $1-4$, where $1=$ Never to $4=$ Almost Always. There is some evidence for the validity of the SMRS measure, as shown by correlations with similar constructs in the current dataset; SMRS is linked both to social media usage $(r=.44, \mathrm{p}<.01)$ as well as psychological distress $(r=.42, \mathrm{p}<.01)$.

Social Media Use. Frequency of adolescents' social media use was measured with the General Social Media Usage subscale from the Media and Technology Usage and Attitudes Scale (Rosen, Whaling, Carrier, Cheever, \& Rokkum, 2013). This 9-item subscale assesses how often participants take part in activities on social media platforms (e.g., post social media status updates, click "like" to a social media posting). Participants report this frequency of activities by indicating a 10-point scale ranging from $1=$ never to $10=$ all the time. The current study shows internal consistency was high $(\alpha=.91)$.

Psychological Distress. Psychological distress was measured with the K6+. This measure of distress consists of six items and was developed for use in the U.S. National Health Interview Survey (Kessler et al., 2002). Participants answered the sentence stem, "During the past 30 days, about how often did you feel ..." with traits like "nervous" and "hopeless" from 1 $=$ all the time to $5=$ none of the time. Participants' scores were calculated by summing all six scores after converting items indicating $0=$ none of the time and $4=$ all the time. Clinical scores 
greater than 12 indicate the likely presence of a mental illness, defined as a DSM-IV disorder occurring in the last 12 months (Prochaska, Sung, Max, Shi, \& Ong, 2012; Mitchell \& Beals, 2011). In the current study, internal consistency was acceptable $(\alpha=.84)$.

\section{Procedure}

During August and September of 2018 and January of 2019, at-risk youth (aged 15-19) completed pretest and posttest survey data. Parent permission, child assent, and informed verbal consent are obtained for participants to be included in the education program and research study. Participants met with a group of students, a facilitator with a background in social work, and an undergraduate student helper one day per week. Researchers communicated the voluntary nature of the surveys through a video presentation and handed out the Qualtrics surveys that are uploaded on iPads. Participants completed questionnaires assessing social media rumination and life-goal orientation and received a $\$ 10$ gift card as an incentive. Participant identification numbers were used to link data across waves. 


\section{CHAPTER III: RESULTS}

\section{Preliminary Analyses}

We calculated means, standard deviations, and zero-order correlations for all study variables (Table 1). A confirmatory factor analysis was conducted in Mplus7 (Muthén \& Muthén, 1998-2012) to examine factor loadings of the Aspiration Index onto intrinsic and extrinsic factors. This analysis indicated the items on the Aspiration Index intended to measure intrinsic and extrinsic life-goal orientation loaded on the appropriate factors at .40 or greater except for one intrinsic life-goal item and one extrinsic life-goal item (cf. Galston, 2010); however, statistical significance for all factor loadings except for one intrinsic life-goal item was $p<.001$.

\section{Primary Analyses}

A cross-lag analysis was conducted in Mplus 7 (Muthén \& Muthén, 1998-2012) to determine the relationship between MVO and social media rumination over time across two waves (pre-program and post-program). An adjusted MVO variable was created to specify the importance of extrinsic life-goals relative to intrinsic life goals; this variable was created by subtracting participants' intrinsic life goal score from their extrinsic life-goal score. I hypothesized that those adolescents with a higher MVO score at Wave 1 will ruminate more over their social media at Wave 2 than adolescents with a lower MVO score at Wave 1.

A cross-lagged panel design assesses the paths between MVO and social media rumination within the same wave (i.e., pretest MVO with pretest social media rumination and posttest MVO with posttest social media rumination), the path between these two variables between the two waves (i.e., pretest MVO with posttest social media rumination and pretest social media rumination with posttest MVO), and the paths from each variables across both 
waves (i.e., pretest MVO and posttest social media rumination and pretest social media rumination and posttest MVO), which are known as autoregressive paths (See Figure 1). Variables such as age, gender, and race/ethnicity were added as covariates.

The cross-lag analysis utilizes a path analysis model with manifest variables, which provides the researchers with indicators of the magnitude of relationships between social media rumination and MVO across time. To determine model fit, cutoff values for the Comparative Fit Index (CFI) and the Tucker-Lewis Index (TLI) were for values of .95 or greater, and for the Standardized Root Mean Square Residual (SRMR), values of .08 or less (Hu \& Bentler, 1999).

Four individuals were excluded from analyses because of low social media usage: three reported never using social media at Wave 1 and Wave 2, and one individual reported very low social media usage at Wave 1 and reported never using social media at Wave 2. Among the remaining participants, missing data was minimal $(n=1)$, and was accounted for in analyses by utilizing full information maximum likelihood (FIML; Acock, 2005). Univariate and multivariate outliers were also considered. Descriptive analyses indicated two individuals were univariate outliers (i.e., z-scores above 3 on constructs of interest); however, results did not substantially change in all models when these two participants were removed, so these data points were included in subsequent analyses. Influential participants were also examined via MPLUS 7 to determine which participants demonstrated the most change from Wave 1 to Wave 2 (Cook, 1979). Results indicated one participant may have reported highly decreased social media rumination from Wave 1 to Wave 2, while another participant may have reported highly decreased MVO from Wave 1 to Wave 2. This suggests that larger samples may be useful for replicating any inferential results.

Model A, examined the path from Wave 1 MVO to Wave 2 MVO and Wave 1 social 
media rumination to Wave 2 social media rumination showed inadequate fit (i.e., SRMR $>.08$ ), $\chi^{2}(1, N=115)=8.32, p=0.040 ; \mathrm{CFI}=0.97 ; \mathrm{TLI}=0.96 ; \mathrm{SRMR}=0.12$. Wave $1 \mathrm{MVO}$ significantly predicted Wave $2 \mathrm{MVO}, \beta=0.80, \mathrm{SE}=0.03, p<0.001$. Wave 1 social media rumination significantly predicted Wave 2 social media rumination, $\beta=0.70, \mathrm{SE}=0.05, p<$ 0.001 .

Model B, which adds from Model A the path from Wave 1 MVO to Wave 2 social media, showed adequate fit $\chi^{2}(1, N=115)=3.27, p=0.195 ; \mathrm{CFI}=0.99 ; \mathrm{TLI}=0.98 ; \mathrm{SRMR}=$ 0.08. Wave $1 \mathrm{MVO}$ significantly predicted Wave $2 \mathrm{MVO}, \beta=0.81, \mathrm{SE}=0.03, p<0.001$. Wave 1 social media rumination significantly predicted Wave 2 social media rumination, $\beta=0.67, \mathrm{SE}$ $=0.05, \mathrm{p}<0.001$. Wave 1 MVO significantly predicted Wave 2 social media rumination, $\beta=$ $0.16, \mathrm{SE}=0.07, \mathrm{p}=0.025$

Model C, which adds from Model A the path from Wave 1 social media rumination to Wave 2 MVO, showed less than adequate fit (i.e., TLI $<.95), \chi^{2}(1, N=115)=8.21, \mathrm{p}=0.017$; $\mathrm{CFI}=0.97 ; \mathrm{TLI}=0.92 ; \mathrm{SRMR}=0.11$. Wave $1 \mathrm{MVO}$ significantly predicted Wave $2 \mathrm{MVO}, \beta=$ $0.80, \mathrm{SE}=0.04, \mathrm{p}<0.001$. Wave 1 social media rumination did not significantly predict Wave 2 $\mathrm{MVO}, \beta=0.02, \mathrm{SE}=0.06, p=0.737$. Wave 1 social media rumination significantly predicted Wave 2 social media rumination, $\beta=0.70, \mathrm{SE}=0.05, p<0.001$.

Model D, as expected the fully saturated model showed adequate fit, $\chi^{2}(1, N=115)=$ $3.20, p=0.074 ; \mathrm{CFI}=1.00 ; \mathrm{TLI}=0.94 ; \mathrm{SRMR}=0.08$. Wave 1 MVO significantly predicted Wave $2 \mathrm{MVO}, \beta=0.80, \mathrm{SE}=0.03, p<0.001$. Wave 1 social media rumination did not significantly predict Wave $2 \mathrm{MVO}, \beta=0.02, \mathrm{SE}=0.06, p=0.794$. Wave 1 social media rumination significantly predicted Wave 2 social media rumination, $\beta=0.68, \mathrm{SE}=0.05, \mathrm{p}<$ 0.001. Wave $1 \mathrm{MVO}$ also significantly predicted Wave 2 social media rumination, $\beta=0.16, \mathrm{SE}$ 
$=0.07, p=0.026$.

A Wald Test was conducted to measure if the strength of association between Wave 1 MVO to Wave 2 social media rumination and Wave 1 social media rumination to Wave 2 MVO in Model D was equivalent. Results show the strength of this association is not significantly different $\left(\chi^{2}(1)=.153, p=.695\right)$

A

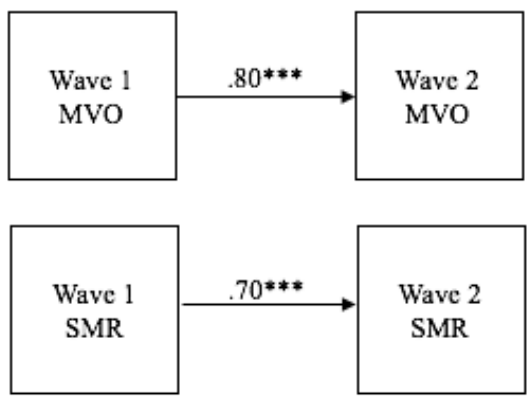

$\mathrm{C}$

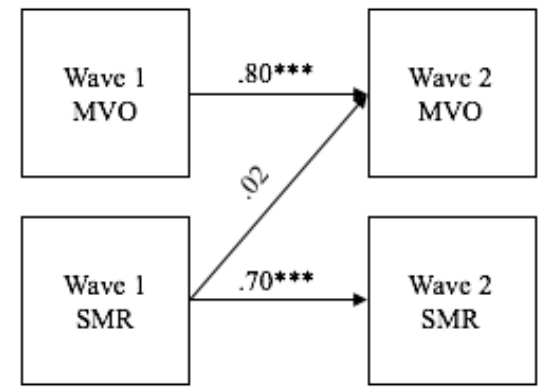

B

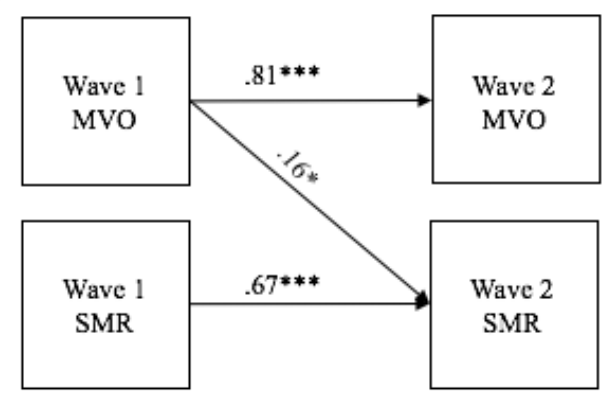

D

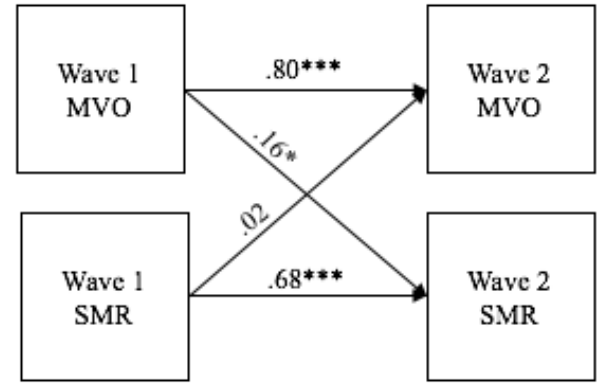

Figure 1: All Models Tested. Wave $1 \mathrm{MVO}=$ Wave 1 materialistic value orientation; Wave 2 $\mathrm{MVO}=$ Wave 2 materialistic value orientation; Wave $1 \mathrm{SMR}=$ Wave 1 social media rumination; Wave $2 \mathrm{SMR}=$ Wave 2 social media rumination. $\mathrm{A}=$ autoregressive model, $\mathrm{B}=$ hypothesized cross-lagged model, $\mathrm{C}=$ alternative cross-lagged model, $\mathrm{D}=$ fully saturated cross-lagged model. Standardized values shown. ${ }^{*} p<0.05, * * p<0.01, * * * p<.001$ 


\section{CHAPTER IV: DISCUSSION}

The purpose of this study was to investigate if MVO is linked to greater social media rumination in adolescents over time. Consistent with my hypotheses, results of the cross-lag analysis indicated that adolescents who reported higher MVO at Wave 1 reported significantly greater social media rumination at Wave 2 than adolescents who reported lower MVO at Wave 1. However, the path from Wave 1 social media rumination to Wave $2 \mathrm{MVO}$ was not significant, suggesting that MVO may have directional influence on social media rumination in adolescents. These findings support SDT (Deci \& Ryan, 2000), which states that those who are not meeting their basic psychological needs will substitute those needs with external validation, seeking approval about physical appearance and materials owned. Those who prioritize MVO may not be satisfying their basic psychological needs, because they are more interested in outward appearance than intrinsic life-goals (Kasser, 2016). SDT suggests a connection between social media rumination and MVO. Maladaptive rumination, or toxic brooding (Nolen-Hoeksema, 1991), and MVO, or over-prioritizing materialistic goals (Kasser, 2016), may be linked in that those who value external validation more than internal satisfaction may compare themselves to others. For example, using Facebook more may lead to social comparison (Vogel et al., 2015), and constant comparison can lead to rumination and identity distress (Yang et al., 2018).

Alternatively, it is also possible that MVO is a learned behavior, as individuals may see influential people striving for more fame and money while appearing satisfied or happy with their life. Observing this status of others may present temptation to believe that fame, materials, and money will make one happy. In this study, those who were higher in MVO may have ruminated over social media more because they sought this external validation on social media platforms through curating the perfect look or interacting on social media platforms to appear of 
higher status. The present study's findings align with past studies that have suggested those who view their friends engaging with each other, but without them, is linked to extrinsic motivation (Alt, 2015). This association may suggest that those with higher MVO may seek external validation through social media platforms, because they want to fit in with others (Richins \& Dawson, 1992; Deci \& Ryan, 2000).

The relationship between higher MVO and more social media rumination may also reflect motivations for external validation that social media platforms promote, such as getting likes or positive comments on a posted photograph or followers for one's posts (Chua \& Chang, 2016). Though interacting with others around the world through these platforms provides an opportunity to connect with others, those who are not meeting their basic psychological needs may use social media platforms to substitute relatedness, autonomy, and competence. In turn, this type of usage may cause psychological distress (Yang et al., 2018); subsequently, interventions regarding strategies to meet basic psychological needs may be necessary for adolescents. Interventions may also combat the damage that maladaptive rumination can exacerbate such as psychological distress and impediment on anxious and depressive symptom coping (Grierson et al., 2016; Mazzer et al., 2019). Therefore, life-goal orientation and rumination may be targets for treatment in school settings and otherwise.

\section{Implications}

The present study has important implications for interventions aimed at ameliorating problems with social media use in adolescents. These present findings indicate at-risk adolescents who ruminate over their social media postings may be doing so because they are seeking external validation rather than meeting basic psychological needs such as relatedness, competence, autonomy. Therefore, increasing youth's awareness and importance of intrinsic life- 
goals may decrease their rumination of social media over time. Creating and achieving shortterm goals that align with broader intrinsic goals could be a useful strategy, as those who set materialistic goals have been shown to have higher Facebook use (Ozimek \& Förster, 2017). Support and mentorship through this process may be a necessary component of intervention as well, as having a trusted adult and positively ending that trusted relationship generally facilitates higher well-being in adolescents (DuBois, Portillo, Rhodes, Silverthorn, \& Valentine, 2011). Teaching youth the importance of meeting intrinsic needs, and deprioritizing materialistic values, may help decrease the weight adolescents place on their social media activity given these findings. Programs in schools could be beneficial for delivering this education, as beginning this education early and implementing it throughout schooling could increase awareness of one's value orientation. For example, exposure to materialistic values may increase one's MVO; therefore, decreasing materialistic messages in schools may decrease students' level of MVO (Kasser, 2016). Additionally, exposure to role models who endorse intrinsic values may reduce MVO (Huta, 2012; Morgenroth, Ryan, \& Peters, 2015), suggesting the need for presence of individuals in schools that demonstrate holding more intrinsic values. Advertisements can also increase MVO (Chia, 2010), suggesting that blocking advertisements on school computers may combat the tendency to seek external validation.

Another strategy that may decrease MVO is bolstering students' sense of security in themselves, as those who feel threatened are more likely to hold materialistic values (Kasser, 2016) and may also be more defensive to interventions that threaten their sense of identity (Sherman \& Cohen, 2006). Avoiding experiences is also linked to materialism (Kashdan \& Breen, 2007), and mindfulness activities can increase a sense of positive self-concept in youth (Schonert-Reichl \& Lawlor, 2010). In turn, mindfulness can reduce one's MVO. Such 
mindfulness activities can be facilitated in schools through packaged programs like Mindfulness Education and BREATHE, which are evidenced to decrease stress in at-risk adolescence (Schonert-Reichl \& Lawlor, 2010; Broderick \& Metz, 2009; Bluth et al., 2016) and can guide school professionals. Through such programs, students often form trusting relationships with adults that help them feel validated in their emotions and experiences and can help reduce materialistic values (Bluth et al., 2016).

Further, helping youth develop a realistic expectation of theirs and others' physical images may reduce MVO in adolescents. This could be worked towards by using diverse photos of students in school promotions, posters in the school building, and other places students may typically see "perfect" people. This strategy, and others discussed, may help reduce the urge for adolescents to compare themselves to unrealistic standards, decreasing the chance they may strive to appear like others and improving their well-being.

\section{Limitations and Future Directions}

There are several limitations to this study. First, the sample size lacks power to measure these constructs as latent variables, the latter of which may account for measurement error. A larger sample size may be utilized in future studies to analyze materialistic value orientation and social media rumination while measuring error. Including more participants may also provide a better picture of the population. Second, the population may not encompass adolescents across the United States, as participants were majority African American females in a medium-sized Midwestern city. Low-income youth may be more susceptible to materialistic values, as they could be more likely to be impacted by interpersonal influence (Isaksen \& Roper, 2008).

Cultures of more rural areas, different parts of the country, and the male perspective may impact results with a new sample. Younger participants may also be included in future work, as high 
school students' independence, compared to middle school or upper elementary students, could be more susceptible to materialistic values. Third, future work may compare other adolescents that have not received relationship education to assess how such a program impacts results. Participants in this study voluntarily enrolled in a relationship education program, which could indicate a willingness to fulfill intrinsic needs (e.g., relatedness), suggesting the sample may be skewed away from MVO and the effect is actually less than that observed. Fourth, some variables are excluded from this study that may be impacting why adolescents spend several minutes thinking about theirs and others' posts on social media platforms and exactly which materialistic values they hold. Qualitative methods, such as drawing a picture of their future or writing goals for themselves could potentially help to investigate adolescents' level of MVO.

\section{Conclusion}

This study sought to investigate the association between MVO and social media rumination over time. Results show at-risk adolescents who align more with MVO are more likely to ruminate on social media across two waves of time. These results indicate adolescents with MVO could benefit from intervention to reduce the effects of their need for external validation and maladaptive rumination, which is linked to behaviors and thoughts that can be harmful to youth's functioning. Prioritizing materialistic values is shown to increase social media rumination, which may be impacting adolescents' psychological distress. Assessing adolescents' life-goal orientation and intervening appropriately may benefit their quality of life. Finally, social media usage is increasingly important for youth navigating the transition to adulthood, indicating the urgency to understand its predictors and outcomes. 


\section{REFERENCES}

Acock, A. C. (2005). Working with missing values. Journal of Marriage and Family, 67, 10121028. http://doi.org/10.1111/j.1741-3737.2005.00191

Alt, D. (2015). College students' academic motivation, media engagement and fear of missing out. Computers in Human Behavior, 49, 111-119. http://doi.org/10.1016/j.chb.2015.02.057

Anderson, M., \& Jiang, J. (2018). Teens, social media \& technology 2018. Pew Research Center, 31, 2018.

Bluth, K., Campo, R. A., Pruteanu-Malinici, S., Reams, A., Mullarkey, M., \& Broderick, P. C. (2016). A school-based mindfulness pilot study for ethnically diverse at-risk adolescents. Mindfulness, 7(1), 90-104. http://doi.org/10.1007/s12671-014-0376-1

Broderick, P. C., \& Metz, S. (2009). Learning to BREATHE: A pilot trial of a mindfulness curriculum for adolescents. Advances in school mental health promotion, 2(1), 35-46.

Brown, K. W., \& Ryan, R. M. (2003). The benefits of being present: mindfulness and its role in psychological well-being. Journal of personality and social psychology, 84(4), 822. https://doi.org/10.1037/0022-3514.84.4.822

Burnette, J. L., Davis, D. E., Green, J. D., Worthington Jr, E. L., \& Bradfield, E. (2009). Insecure attachment and depressive symptoms: The mediating role of rumination, empathy, and forgiveness. Personality and Individual Differences, 46(3), 276-280.

https://doi.org/10.1016/j.paid.2008.10.016

Chaplin, L. N., \& John, D. R. (2007). Growing up in a material world: Age differences in materialism in children and adolescents. Journal of Consumer Research, 34(4), 480-493. 
Chia, S. C. (2010). How social influence mediates media effects on adolescents' materialism. Communication Research, 37(3), 400-419. https://doi.org/10.1177/0093650210362463

Chua, T. H. H., \& Chang, L. (2016). Follow me and like my beautiful selfies: Singapore teenage girls' engagement in self-presentation and peer comparison on social media. Computers in Human Behavior, 55, 190-197. https://doi.org/10.1016/j.chb.2015.09.011

Cook, R. D. (1979). Influential observations in linear regression. Journal of the American Statistical Association, 74, 169-174.

Deci, E. L., \& Ryan, R. M. (2000). The "what" and" why" of goal pursuits: Human needs and the self-determination of behavior. Psychological inquiry, 11(4), 227-268.

Deci, E. L., \& Ryan, R. M. (2012). Self-determination theory. In Handbook of Theories of Social Psychology, (Vol. 1). London: SAGE Publications Ltd.

DeJong, H., Fox, E., \& Stein, A. (2019). Does rumination mediate the relationship between attentional control and symptoms of depression?. Journal of Behavior Therapy and Experimental Psychiatry, 63, 28-35. https://doi.org/10.1016/j.jbtep.2018.12.007

DuBois, D. L., Portillo, N., Rhodes, J. E., Silverthorn, N., \& Valentine, J. C. (2011). How effective are mentoring programs for youth? A systematic assessment of the evidence. Psychological Science in the Public Interest, 12(2), 57-91. https://doi.org/10.1177/1529100611414806

Espinoza, G., \& Juvonen, J. (2011). The pervasiveness, connectedness, and intrusiveness of social network site use among young adolescents. Cyberpsychology, Behavior, and Social Networking, 14(12), 705-709. https://doi.org/10.1089/cyber.2010.0492 
Feinstein, B. A., Bhatia, V., \& Davila, J. (2014). Rumination mediates the association between cyber-victimization and depressive symptoms. Journal of Interpersonal Violence, 29(9), 1732-1746. https://doi.org/10.1177/0886260513511534

Feinstein, B. A., Hershenberg, R., Bhatia, V., Latack, J. A., Meuwly, N., \& Davila, J. (2013). Negative social comparison on Facebook and depressive symptoms: Rumination as a mechanism. Psychology of Popular Media Culture, 2(3), 161. https://doi.org/10.1037/a0033111

Grierson, A. B., Hickie, I. B., Naismith, S. L., \& Scott, J. (2016). The role of rumination in illness trajectories in youth: linking trans-diagnostic processes with clinical staging models. Psychological Medicine, 46(12), 2467-2484.

https://doi.org/10.1017/S0033291716001392

Hayton, J. C., Allen, D. G., \& Scarpello, V. (2004). Factor retention decisions in exploratory factor analysis: A tutorial on parallel analysis. Organizational Research Methods, 7(2), 191-205. https://doi.org/10.1177/1094428104263675

Hu, L. T., \& Bentler, P. M. (1999). Cutoff criteria for fit indexes in covariance structure analysis: Conventional criteria versus new alternatives. Structural Equation Modeling: a multidisciplinary journal, 6(1), 1-55. https://doi.org/10.1080/10705519909540118

Huta, V. (2012). Linking peoples' pursuit of eudaimonia and hedonia with characteristics of their parents: Parenting styles, verbally endorsed values, and role modeling. Journal of Happiness Studies: An Interdisciplinary Forum on Subjective Well-Being, 13(1), 47-61. https://doi.org/10.1007/s10902-011-9249-7

Isaksen, K. J., \& Roper, S. (2008). The impact of branding on low-income adolescents: A vicious cycle?. Psychology \& Marketing, 25(11), 1063-1087. 
Kamal, S., Chu, S. C., \& Pedram, M. (2013). Materialism, attitudes, and social media usage and their impact on purchase intention of luxury fashion goods among American and Arab young generations. Journal of Interactive Advertising, 13(1), 27-40. https://doi.org/10.1080/15252019.2013.768052

Kashdan, T. B., \& Breen, W. E. (2007). Materialism and diminished well-being: Experiential avoidance as a mediating mechanism. Journal of Social and Clinical Psychology, 26(5), 521-539. https://doi.org/10.1521/jscp.2007.26.5.521

Kasser, T. E., \& Kanner, A. D. (2004). Psychology and consumer culture: The struggle for a good life in a materialistic world. Washington, D.C.: American Psychological Association.

Kasser, T., \& Ryan, R. M. (1993). A dark side of the American dream: Correlates of financial success as a central life aspiration. Journal of Personality and Social Psychology, 65(2), 410. https://doi.org/10.1037/0022-3514.65.2.410

Kasser, T. (2016). Materialistic values and goals. Annual Review of Psychology, 67, 489514. https://doi.org/10.1146/annurev-psych-122414-033344

Kessler, R. C., Andrews, G., Colpe, L. J., Hiripi, E., Mroczek, D. K., Normand, S. L., ... \& Zaslavsky, A. M. (2002). Short screening scales to monitor population prevalences and trends in non-specific psychological distress. Psychological Medicine, 32(6), 959-976. https://doi.org/10.1017/S0033291702006074

Lannin, D.G., Parris, L., Yazedjian, A., \& Hynes, K. (under review). Youth online activity and distress: The role of social media rumination. Journal of Adolescent Health.

León, J., \& Núñez, J. L. (2013). Causal ordering of basic psychological needs and well-being. Social Indicators Research, 114(2), 243-253. https://doi.org/10.1007/s11205-012-0143 
Luyckx, K., Duriez, B., Green, L. M., \& Negru-Subtirica, O. (2017). Identity processes and intrinsic and extrinsic goal pursuits: directionality of effects in college students. Journal of Youth and Adolescence, 46(8), 1758-1771. https://doi.org/10.1007/s10964-016-0626-8

Mazzer, K., Boersma, K., \& Linton, S. J. (2019). A longitudinal view of rumination, poor sleep and psychological distress in adolescents. Journal of Affective Disorders, 245, 686696. https://doi.org/10.1016/j.jad.2018.11.05

McLaughlin, K. A., \& Nolen-Hoeksema, S. (2011). Rumination as a transdiagnostic factor in depression and anxiety. Behaviour Research and Therapy, 49(3), 186-193. https://doi.org/10.1016/j.brat.2010.12.006

McNicol, M. L., \& Thorsteinsson, E. B. (2017). Internet addiction, psychological distress, and coping responses among adolescents and adults. Cyberpsychology, Behavior, and Social Networking, 20(5), 296-304. https://doi.org/10.1089/cyber.2016.0669

Mitchell, C. M., \& Beals, J. (2011). The utility of the Kessler Screening Scale for Psychological Distress (K6) in two American Indian communities. Psychological Assessment, 23(3), 752. https://doi.org/10.1037/a0023288

Mitra, R., \& Rangaswamy, M. (2019). Excessive Social Media use and its Association with Depression and Rumination in an Indian Young Adult Population: A Mediation Model. Journal of Psychosocial Research, 14(1), 223-

231. https://doi.org/10.32381/JPR.2019.14.01.24

Morgenroth, T., Ryan, M. K., \& Peters, K. (2015). The motivational theory of role modeling: How role models influence role aspirants' goals. Review of General Psychology, 19(4), 465-483. https://doi.org/10.1037/gpr0000059 
Muthén, L.K. and Muthén, B.O. (1998-2012). Mplus User's Guide. Seventh Edition. Los Angeles, CA: Muthén \& Muthén.

Nolen-Hoeksema, S. (1991). Responses to depression and their effects on the duration of depressive episodes. Journal of Abnormal Psychology, 100(4), 569.

Norris, J. I., Lambert, N. M., DeWall, C. N., \& Fincham, F. D. (2012). Can’t buy me love?: Anxious attachment and materialistic values. Personality and Individual Differences, 53(5), 666-669. https://doi.org/10.1016/j.paid.2012.05.009

Ozimek, P., \& Förster, J. (2017). The impact of self-regulatory states and traits on Facebook use: Priming materialism and social comparisons. Computers in Human Behavior, 71, 418427. https://doi.org/10.1016/j.chb.2017.01.056

Pearson, M. (2016). Love notes. The Dibble Institute for Marriage Education.

Prochaska, J. J., Sung, H. Y., Max, W., Shi, Y., \& Ong, M. (2012). Validity study of the K6 scale as a measure of moderate mental distress based on mental health treatment need and utilization. International Journal of Methods in Psychiatric Research, 21(2), 88-97. https://doi.org/10.1002/mpr.1349

Richins, M. L., \& Dawson, S. (1992). A consumer values orientation for materialism and its measurement: Scale development and validation. Journal of Consumer Research, 19(3), 303-316.

Rosen, L. D., Whaling, K., Carrier, L. M., Cheever, N. A., \& Rokkum, J. (2013). The media and technology usage and attitudes scale: An empirical investigation. Computers in Human Behavior, 29(6), 2501-2511. https://doi.org/10.1016/j.chb.2013.06.006 
Schonert-Reichl, K. A., \& Lawlor, M. S. (2010). The effects of a mindfulness-based education program on pre-and early adolescents' well-being and social and emotional competence. Mindfulness, 1(3), 137-151. https://doi.org/10.1007/s12671-010-0011-8

Shaw, A. M., Timpano, K. R., Tran, T. B., \& Joormann, J. (2015). Correlates of Facebook usage patterns: The relationship between passive Facebook use, social anxiety symptoms, and brooding. Computers in Human Behavior, 48, 575-580. https://doi.org/10.1016/j.chb.2015.02.003

Sheldon, K. M., Sommet, N., Corcoran, M., \& Elliot, A. J. (2018). Feeling interpersonally controlled while pursuing materialistic goals: A problematic combination for moral behavior. Personality and Social Psychology Bulletin, 44(9), 1330-1349. https://doi.org/10.1177/0146167218766863

Sherman, D. K., \& Cohen, G. L. (2006). The psychology of self-defense: Self-affirmation theory. Advances in Experimental Social Psychology, 38, 183-242.

Tsang, J. A., Carpenter, T. P., Roberts, J. A., Frisch, M. B., \& Carlisle, R. D. (2014). Why are materialists less happy? The role of gratitude and need satisfaction in the relationship between materialism and life satisfaction. Personality and Individual Differences, 64, 6266. https://doi.org/10.1016/j.paid.2014.02.009

Twenge, J. M., Campbell, W. K., \& Freeman, E. C. (2012). Generational differences in young adults' life goals, concern for others, and civic orientation, 1966-2009. Journal of Personality and Social Psychology, 102(5), 1045-1062. https://doi.org/10.1037/a0027408 
Vogel, E. A., Rose, J. P., Okdie, B. M., Eckles, K., \& Franz, B. (2015). Who compares and despairs? The effect of social comparison orientation on social media use and its outcomes. Personality and Individual Differences, 86, 249-256. https://doi.org/10.1016/j.paid.2015.06.026

Vogel, E. A., Rose, J. P., Roberts, L. R., \& Eckles, K. (2014). Social comparison, social media, and self-esteem. Psychology of Popular Media Culture, 3(4), 206. https://doi.org/10.1037/ppm0000047

VonHoltz, L. A. H., Frasso, R., Golinkoff, J. M., Lozano, A. J., Hanlon, A., \& Dowshen, N. (2018). Internet and social media access among youth experiencing homelessness: Mixed-methods study. Journal of Medical Internet Research, 20(5). https://doi.org/10.2196/jmir.9306

Wang, P., Wang, X., Zhao, M., Wu, Y., Wang, Y., \& Lei, L. (2018). Can social networking sites alleviate depression? The relation between authentic online self-presentation and adolescent depression: A mediation model of perceived social support and rumination. Current Psychology, 1-10. https://doi.org/10.1007/s12144-017-9711-8

Wei, M., Shaffer, P. A., Young, S. K., \& Zakalik, R. A. (2005). Adult attachment, shame, depression, and loneliness: The mediation role of basic psychological needs satisfaction. Journal of Counseling Psychology, 52(4), 591. https://doi.org/10.1037/0022$\underline{0167.52 .4 .591}$

Yang, C. C., Holden, S. M., Carter, M. D., \& Webb, J. J. (2018). Social media social comparison and identity distress at the college transition: A dual-path model. Journal of Adolescence, 69, 92-102. https://doi.org/10.1007/s10964-017-0801-6 
APPENDIX A: SOCIAL MEDIA RUMINATION, MATERIALISTIC VALUE ORIENTATION, AND DEMOGRAPHICS

Table 1

Social Media Rumination, Materialistic Value Orientation, and Demographics

\begin{tabular}{llcccccc} 
Mean & SD & 1 & 2 & 3 & 4 & 5 & 6 \\
2.74 & .78 & - & & & & & \\
15.84 & .83 & $.89 * * *$ & - & & & \\
2.08 & 1.27 & .12 & .14 & - & & \\
-1.95 & 1.25 & .01 & .04 & $.80^{* * *}$ & - & \\
1.68 & .70 & -.07 & .04 & .17 & .16 & - & \\
1.68 & .57 & .08 & -.07 & $.26^{* *}$ & $.28^{* *}$ & $.70^{* * *}$ & - \\
\hline
\end{tabular}

Note. Pearson's product-moment correlation are reported above when either variable was continuous; When both variables were binary, we conducted Spearman's rank-order correlations; SD = standard deviation; W1 = Wave 1, W2 = Wave 2; SMR = social media rumination, $\mathrm{MVO}=$ materialistic value orientation. Grades were coded as $1=$ freshman, $2=$ sophomore, $3=$ junior, $4=$ senior. ${ }^{*} p<.05 . * * p<.01 . * * * p<.001$. 


\section{APPENDIX B: MATERIALISTIC VALUE ORIENTATION AND SOCIAL MEDIA RUMINATION}

Table 2

Materialistic value orientation and social media rumination

\begin{tabular}{|c|c|c|c|c|c|c|}
\hline & Mean & SD & 1 & 2 & 3 & 4 \\
\hline 1. W1 MVO & -2.08 & 1.27 & - & & & \\
\hline 2. $\mathrm{W} 2 \mathrm{MVO}$ & -1.95 & 1.25 & $.80 * * *$ & - & & \\
\hline 3. W1 SMR & 1.68 & .57 & .17 & .16 & - & \\
\hline 4. W2 SMR & 1.68 & .70 & $.26^{* *}$ & $.28 * *$ & $.70 * * *$ & - \\
\hline
\end{tabular}

Note. Pearson's product-moment correlation are reported above when either variable was continuous; When both variables were binary, we conducted Spearman's rank-order correlations; SD = standard deviation; W1 = Wave 1, W2 = Wave 2; SMR = social media rumination, $\mathrm{MVO}=$ materialistic value orientation. ${ }^{*} p<.05 .{ }^{*} p<.01 . * * * p<.001$. 